\title{
How Big is Big Enough? Limits to Cell Size
}

\author{
Debarshi Dasgupta* \\ Centre for Ecological Sciences, Indian Institute of Science, Bengaluru, India \\ *Corresponding author
}

\begin{abstract}
A B S T R A C T

\begin{tabular}{|l|}
\hline Ke y w or d s \\
Size, Volume, \\
Cells, Cellular \\
architecture
\end{tabular}
\end{abstract}

\section{Introduction}

When Heide Schulz and her co-workers from the Max Planck Institute for Marine Microbiology accidentally discovered Thiomargarita namibiensis from the coastal sediments of Walvis Bay in Namibia (Schulz et al., 1999), it created ripples in the scientific community. Firstly, it ended the decade-old reign of Epulopiscium fishelsoni as the largest known bacterium at that time. Till date, the smallest eukaryotic cell found in nature has been from the algal genus Ostreococcus, which is only $0.8 \mu \mathrm{m}$ in diameter. $T$. namibiensis has a diameter of $750 \mu \mathrm{m}$, which is almost 9 times that of a human ovum. Therefore, the confusion is quite obvious: What is the highest limit to the size of a cell? Is there any possible limit to the size of a prokaryote cell? Lastly, how can a cell almost $0.1 \mathrm{~mm}$ in size (which is slightly visible to the naked eye) manage to remain a "prokaryote"?

The logic behind the small size of cells is fairly self-explanatory. Maximum transport rates of nutrients across a cell surface increases with surface area. On the contrary, an increase in volume would lead to a higher nutritional demand. A cell needs to accommodate the basic machinery and materials required for its survival, growth and development. This limits the lower boundary of a possible cell-size. The maximum possible size of a cell is bound by the limits of diffusion which triggers acquisition of nutrients, elimination of wastes and movements of biomolecules within the cell. For the movement of molecules over few 
microns inside the cell, diffusion is very efficient. Due to its short mixing time in diffusion, a biomolecule reaches its site of activity within an instant. However, if we consider dimensions of Thiomargarita or Epulopiscium, then diffusion becomes a notso-reliable approach. The time taken for the diffusing molecule varies with the square of the distance it has to traverse. An oxygen molecule, that traverses a $1 \mu \mathrm{m}$ width in $10^{-3}$ second, will take almost an hour to diffuse $1 \mathrm{~mm}$ which is close to the giant bacteria dimensions. While all cells tend to be small with a large surface area relative to their cytoplasmic volume, the large bacteria do not conform to this general pattern.

The word "Thiobacteria" means sulphur pearl. The bacterium has been seen to form chains of cells that shine white on a background of black mud, due to the presence of sulphur globules which refract light, resembling a string of pearls. T. namibiensis appears in deep sea sediments, in oxygenpoor environments with high sulphate reduction rates. The interesting feature of these cells is the presence of a large vacuole which makes up almost $95 \%$ of the biovolume. This vacuole acts as a reservoir of nitrate. The cytoplasm remains restricted to 0.5 to $2 \mu \mathrm{m}$ thickness, which contains numerous sulphur globules. Being chemolithotrophic, the bacterium utilises nitrate as a terminal electron acceptor and oxidises hydrogen sulphide to elemental sulphur which accumulates in the cells. This thin cytoplasm is a very subtle response to the aforesaid problem of slowing of diffusion over large distances. As no part of the cytoplasm is more than $4 \mu \mathrm{m}$ away from the ambient environment, diffusion can take place fairly quickly. Hence, the earlier concept of surface-to-volume ratio has now given way to the new "surface-to-cytoplasmic ratio". The obvious query is why is there such a large vacuole to store nitrate?
The answer lies in the fact that Thiomargarita is non-motile, unlike other sulphur bacteria like Thioplaca and Beggiatoa. In most of the marine sediments where such bacteria are found, the zones of nitrate and hydrogen sulphide do not overlap. Thioplaca and Beggiatoa, being motile, can shift from locations of sulphide uptake and nitrate uptake. But Thiomargarita being non-motile, rely on passive acquisition of nutrients (like resuspension of loose sediments). Therefore, they store high amounts of sulphur and nitrate within their cells. It can be assumed that when a cell has an abundance of required nutrients around it, then the diffusion limitations might be a bit relaxed, and the organism can grow larger than normal.

The same can also be said about spirochetes which are found in the hindgut of termites. This pattern can explain the variability in sizes of the cells under consideration. In case of Thiomargarita, although individual cells reach up to $750-800 \mu \mathrm{m}$, the average size varies between 100 to $300 \mu \mathrm{m}$. This suggests that within a species, large variations in size can be observed as a result of the varying nutrient levels a cell is exposed to.

A valid issue to be raised is this: if enlargement of cells creates problems in diffusion, then why are eukaryotic cells (10$100 \mu \mathrm{m}$ diameter) larger than those of prokaryotes? Eukaryotes show presence of membrane-bound cell organelles, compartmentalisation of cellular functions and motor protein-facilitated trafficking of molecules in a complex cytoskeleton. This reflects J.B.S. Haldane's excerpt "they are more complicated because they are large". Many scientists have inconclusively showed a possible relation of cell size to its nucleic acid content. Polyploidy is a very common phenomenon in large cells like Thiomargarita, Epulopiscium, Drosophila salivary gland cells, trichomes etc. In large 
bacteria though, the nucleoid can be present in hundreds of copies. Excess of nucleic acid can mean production of multiple copies of gene products after transcription and translation which may be necessary to cater to the proper functioning of such large cells. If there really is a direct correlation between nucleic acid content and cell size and a proper explanation of effect of polyploidy on cell size, it would explain many of the persisting doubts we have. For example, can a microbe become polyploid when its environment is so nutrient-rich that there is no need to economise on ploidy level? After it achieves a certain level of polyploidy, how can that cell modify its cellular architecture to mediate further increase in cell size?

It boils down to one question: "HOW BIG IS BIG ENOUGH?"

\section{References}

Schulz, H. N., Brinkhoff, T., Ferdelman, T. G., Hernández Mariné, M., Teske and A., Jørgensen, B. B. (1999): Dense Population of a Giant Sulfur Bacterium in Namibian Shelf Sediments. Science 284: $389-544$

\section{How to cite this article:}

Debarshi Dasgupta. 2021. How Big is Big Enough? Limits to Cell Size. Int.J.Curr.Microbiol.App.Sci. 10(02): 1384-1386. doi: https://doi.org/10.20546/ijcmas.2021.1002.165 